\title{
Physicians: Too many or too few?
}

T

I o no one's surprise, the great Canadian health care debate has taken centre stage in the current federal election. Dissatisfaction with waiting lists, emergency services, patient safety and access to primary care are stirring up fervour as the parties try to outbid one another with promises as sweeping as home care, pharmacare and topped-up federal funding, and as particular as "increase[d] medical professional spaces in universities and accelerate[d] qualification of new immigrants with foreign credentials."

There's little political risk in a promise of more doctors: it's a rare voter who would argue we already have enough. But predicting future needs for health care professionals is difficult; many would say impossible. In Canada we've lived through the Barer-Stoddart report of $1991^{2}$ (which was published in an expanded version in a series of articles in CMA7 beginning in 1992), ${ }^{3}$ which predicted an oversupply of physicians and led to reductions in medical school class sizes and postgraduate training positions. More recently we've published predictions of physician shortages ${ }^{4}-$ along with opposing predictions of physician surpluses.

Predictions can be made by looking backward, or imagining forward. Historically based predictions assume that past trends will continue. Thus, to determine the demand for physicians 10 years from now one simply has to use existing projections of future economic growth, which are very highly correlated with physician numbers. In the United States, such projections indicate that there will be a shortage of 50000 physicians by the year $2010 .^{6}$ These predictions also forecast a much greater need for specialists than for family physicians.

Alternatively, one can predict future demand by visualizing an ideal health care system and planning for it. Romanow used this approach when he made his workforce projections in his final report. ${ }^{7}$ His method assumes, rightly, that if health care professionals worked in teams, each profession using its own set of skills (scope of practice) in a complementary fashion along with adequate administrative, clerical and technological support, we would likely not need more physicians. The trouble with this model, of course, is that making it work requires fundamental $\infty$ changes to the culture of health care and of professional education - changes that, despite decades of advocacy, continue to elude us.

Given the impossibility of predicting how many health professionals (and of what mix) will be needed 10 years from now, it is tempting to just keep muddling along. But muddling is not viewed as respectable public policy. Associations of health professionals, universities and the provinces (which have the responsibility and the budgets for education) will be compelled to take a clear policy direction based on estimates of future needs; their decisions will be imperfect, but necessary.

Using most likely a blend of backward- and forwardlooking models, they will need to take into account, in addition to the usual factors of population growth, aging and regional differences, changes within the professions. There is good evidence that over the past decade physicians have become increasingly dissatisfied with the practice of medicine. Although medical school applications remain robust, if the perception of dissatisfaction is real and continues to grow it may become more difficult to recruit outstanding young women and men into the profession.

There is already some evidence that medicine is becoming less appealing. Applications to medical schools are not keeping pace with growth in the number of spots; the latter increased by $31 \%$ between 1999 and 2002, while the number of applications grew by only $2.7 \%$ and the acceptance rate (proportion of applicants accepted) by $28 \% .{ }^{8}$ We need to be wary of plans to increase medical student spots without adequately addressing the problems underlying the growing dissatisfaction. We need improved working conditions and, for some specialties (particularly those in primary care), better financial rewards.

Romanow, recognizing the hazards of predicting physician supply, recommended that we had best stick to shortterm planning and that - given the fact that professionals move easily from province to province (and abroad) - that we do this on a national level through the Canada Health Council. Not a bad idea. - CMAf

\section{References}

1. Liberal Party of Canada. Choose a health care fix for a generation [advertisement]. Globe and Mail [Toronto] 2004 May 29; Sect A:5.

2. Barer ML, Stoddart GL. Toward integrated medical resource policies for Canada. Prepared for the Federal/Provincial/Territorial Conference of Deputy Ministers of Health, 1991.

3. Barer ML, Stoddart GL. Toward integrated medical resource policies for Canada: 1. Background, process and perceived problems. CMAf 1992;146(3): $347-51$.

4. Ryten E, Thurber AD, Buske L. The Class of 1989 and physician supply in Canada. CMA7 1998;158(6):723-8.

5. Evans RG. New bottles, same old wine: right and wrong on physician supply. CMA7 1998;158(6):757-9.

6. Cooper RA, Getzen TE, Laud P. Economic expansion is a major determinant of physician supply and utilization. Health Serv Res 2003;38:675-96.

7. Romanow RJ. Building on values: the future of health care in Canada. Saskatoon: Commission on the Future of Health Care in Canada; 2002. Available: www.healthcarecommission.ca (accessed 2004 June 1).

8. The Association of Canadian Medical Colleges. Admission requirements of Canadian faculties of medicine: admission in 2004. Ottawa; 2004. Available: www.acmc.ca/2004AdmissionReq/2004AdBk.pdf (accessed 2004 June 1). 